\title{
Effect of PCC crystallization and morphology on flocculation with microfibrillated cellulose, on sheet densification and liquid absorption behavior
}

\author{
Teija Laukala (D) J Johanna Lyytikäinen (D) K Katriina Mielonen (D) • \\ Kaj Backfolk
}

Received: 30 April 2020/Accepted: 12 September 2020/Published online: 1 October 2020

(C) The Author(s) 2020

\begin{abstract}
Composite sheets consisting of elongated and aggregated cationically charged precipitated calcium carbonate (PCC) and native microfibrillated cellulose (MFC) were prepared with a wet laying method. The furnishes were prepared with and without an anionic flocculating agent (polyacrylamide) in order to adjust the structure of the sheet. The samples were compressed (densified) in order to determine the particle and microfibrillated cellulose-PCC structure coalescence and densification, as well as its subsequent influence on liquid absorption behavior. The densification affected both the vertical and lateral
\end{abstract}

distribution of PCC, but the flocculating agent enhanced the compression stability and stabilized the sheets against PCC material flow. The differences between the sheets made with and without the flocculation aid affected the absorption of an anionic dye-based fluid ink, which was evident as a higher print density and less print bleeding. The absorption behavior was dependent on the sheet structure, especially on the PCC distribution within the sheets. Finally, the role of MFC on floc structure and floc formation is discussed.

Electronic supplementary material The online version of this article (https://doi.org/10.1007/s10570-020-03458-2) contains supplementary material, which is available to authorized users.

T. Laukala (两) · J. Lyytikäinen · K. Mielonen ·

K. Backfolk

Packaging Technology of LUT School of Energy

Systems, Lappeenranta-Lahti University of Technology,

P.O. Box 20, 53850 Lappeenranta, Finland

e-mail: teija.laukala@lut.fi

K. Backfolk

Stora Enso Oyj Research Center Imatra, 55800 Imatra,

Finland 


\section{Graphic abstract}

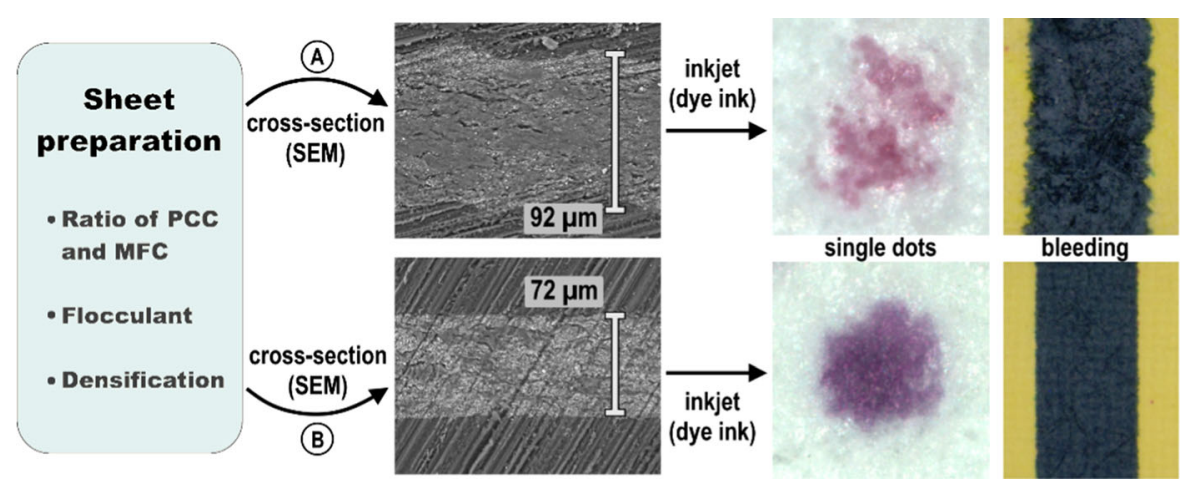

Keywords Microfibrillated cellulose - PCC . Precipitated calcium carbonate $\cdot$ Composite $\cdot$ Dye . Absorption

\section{Introduction}

Calcium carbonate, $\mathrm{CaCO}_{3}$, is an important industrial pigment and filler material in numerous applications, such as plastic-based composites, paints, food, ceramics and the paper industry. Recently, composite materials consisting of $\mathrm{CaCO}_{3}$, microfibers and nanocellulose have gained interest in the search for new ways of improving the water removal from hardto-dewater fiber-based furnishes (Rantanen et al. 2015; Dimic-Misic et al. 2017), substrates for printed electronics (Penttilä et al. 2012; Torvinen et al. 2012, 2015) and transparent films (Gebauer et al. 2011). Additionally, a fairly recently developed cogrinding method of microcellulose (MFC) production is claimed to be industrially scalable, and results in a mixture of MFC and mineral such as $\mathrm{CaCO}_{3}$ (Svending 2014).

Micro and nanofibrillated celluloses (MNFCs) and $\mathrm{CaCO}_{3}$ have also been of interest for paper coating (Lavoine et al. 2014; Mielonen et al. 2018; DimicMisic et al. 2013). MNFC gives a slurry with high viscosity and viscoelastic behavior, although it also poses a lot challenges when used as a binder in mineral based coatings, especially if it is applied using traditional coating processes (Lavoine et al. 2014). However, surfaces of micro- or nano-fibrillated cellulose or composite material of a mineral and MNFC offer interesting possibilities, including greater surface smoothness and uniformity with a simultaneous increase in paper stiffness (Ridgway and Gane 2012), and greater barrier properties e.g. offering low air permeability (Brodin et al. 2014).

For MNFC-mineral nanocomposite sheets, i.e. mineral material and micro or nanofibrillated cellulose prepared to sheets with or without other functional chemicals, properties such as density and porosity can be altered through the selection of particle size and particle size distribution and/or by calendering (Penttilä et al. 2012; Torvinen et al. 2012; Bollström et al. 2019). Timofeev et al. (2014) suggested that microscopic differences in the sheet structure prior to calendering may affect the calendering deformation, which suggests that controlling the MNFC-mineral sheet structure prior to calendering enable the finished (calendered) sheet properties to be finely tuned. This is in agreement with findings related to the calendaring and densification of traditional paper containing filler, as shown by Yang et al (2006), who report the effect of freeness of reinforcement kraft pulp in mineral-filled supercalendered, thermomechanical pulp-based paper smoothness. The authors emphasize the possible effect of filler distribution in the z-direction on paper smoothness, and fiber (lumen) collapse during calendering.

Despite the chemical similarity of certain paper substrates and MNFC-mineral composite sheets, the composite sheets and especially the heavily filled composite sheets can be expected to respond differently to densification with calendering and thus show calendered sheet properties, or calendering potential, different from those of a typical paper substrate. The typical fiber size is significantly smaller in a MNFCmineral nanocomposite sheet, and the fibers lack 
lumens and have extremely high potential to form bonds. The filler content may also be increased in MNFC-mineral sheets, e.g. to $80 \mathrm{wt} \%$ used by Penttilä et al (2012). The differences between the substrates are emphasized when the different calendering mechanisms, such as flattening of the substrate and replication of roll surface, are considered.

The liquid absorption and colorant capture on the surface of the substrate are of importance for producing high image quality in digital printing, and for making functionalities, for example, in printed electronics. Printed functionality such as smart sensors or intelligent tags require a uniform layer of conductive ink to be formed and high precision deposition and spreading of the ink (Torvinen et al. 2012). The high smoothness required for the purpose (Penttilä et al. 2013, Torvinen et al. 2012) can be achieved with calendering, and enhanced dimensional stability can be achieved by use of high filler content (Torvinen et al. 2012).

In such sheets, the ability of micro- or nanofibrillated cellulose to bind the filler has a significant role in ensuring high strength and improving thermal stability (Torvinen et al. 2012). However, forming of porous structures caused by the presence of filler is sometimes associated with increased ink penetration and loss of functionality (Penttilä et al. 2012). This, too, focuses the attention towards calendering, and whether the absorptive properties of the sheet can be improved and controlled with densification in order to optimize the sheet structure for printability. To our knowledge, however, there is relatively little information available on the densification of MNFC-mineral composite sheet structure and its effects on the liquid (ink) absorption of the sheets, especially when the microstructure of the sheet is altered by use of flocculating agents in the sheet preparation phase.

The scope of the present work is to clarify the effect of densification on the microfibrillated cellulosemineral composite sheet structure (including sheet porosity, smoothness and mineral distribution or consolidation in the sheet) and its influence on the liquid (ink) absorption behavior and colorant capture efficiency. The effect of modified sheet microstructure (e.g. agglomeration of the mineral species and microfibrils) on the densification and liquid absorption of the sheets was included.

In order to control and adjust the microstructure of the pre-calendered sheets, composite sheets with different ratio of PCC-to-MFC were made with and without an anionic flocculation additive. A precipitated calcium carbonate was synthesized having a cigar-shaped morphology and different charge sites was prepared and then mixed with microfibrillated cellulose. The substrate-ink/liquid interaction was determined by investigation the absorption behavior into the sheets was and by determining lateral and vertical spreading of water drops.

\section{Materials and methods}

\section{Sample preparation}

\section{PCC precipitation}

A PCC grade with controlled charge, particle size and morphology was synthetized through carbonization of calcium hydroxide $\left(\mathrm{Ca}(\mathrm{OH})_{2}\right)$ in the presence of poly(diallyldimethylammonium chloride) (PDADMAC, Catiofast ${ }^{\circledR}$ BP, BASF GmbH). The polymer was used to control and adjust the PCC charge. Particle morphology, size and size distribution were primarily adjusted through the use of an elevated reaction temperature of $75-80{ }^{\circ} \mathrm{C}$, slurry solids and $\mathrm{CO}_{2}$ feed. The conditions were chosen to obtain cigarshaped PCC particles and aggregates.

The PCC was precipitated in $2000 \mathrm{~g}$ batches (before precipitation) by bubbling with carbon dioxide $\left(\mathrm{CO}_{2}\right.$, AGA, purity $\left.99.7 \%\right)$ in an open batch reactor equipped with heating or cooling jacket for temperature control. Before precipitation, the $\mathrm{Ca}(\mathrm{OH})_{2}$ concentration was $3.7 \mathrm{wt} \%$. The $\mathrm{Ca}(\mathrm{OH})_{2}$ used was prepared from calcium oxide $(\mathrm{CaO}$, Honeywell

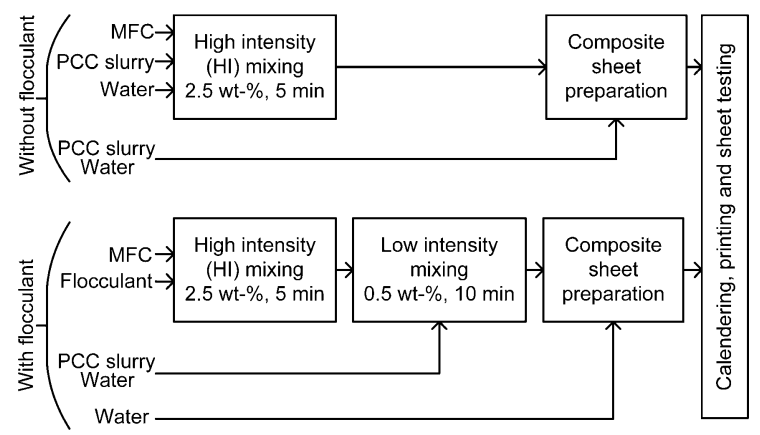

Fig. 1 Scheme of sheet preparation. Weight percentages refer to stock consistency. The sheets prepared and their basic properties are listed in Tables 1 and 2 
reagent grade) by slaking with a ratio of 1-to- $9(\mathrm{CaO}-$ to- $\left.\mathrm{H}_{2} \mathrm{O}\right)$. The $\mathrm{Ca}(\mathrm{OH})_{2}$ slurry was filtered through a metal wire with $63 \mu \mathrm{m}$ openings to remove large particles.

\section{Microfibrillated cellulose}

A microfibrillated cellulose sample was prepared from bleached hardwood kraft pulp from a Finnish pulp mill. The pulp was mechanically refined and further homogenized and micronized by running three times $(2 \times 400 / 200+1 \times 200 / 100 \mu \mathrm{m}$ chambers $)$ through a homogenizer (Microfluidizer M-110EH-30, Microfluidics Corp.) using pressures of 1100 bar and 1500 bar, respectively. The microfibrillated cellulose was anionic (zeta potential $-25 \mathrm{mV}$ when determined in deionized water at $\mathrm{pH} 9.0$ ) and used as received.

\section{Sheet preparation and calendaring}

The scheme of sheet preparation is shown in Fig. 1. The composite sheets were prepared using the equipment described in the SCAN C 26:99 standard, a modified wire (nylon monofilament with $100 \mu \mathrm{m}$ opening, Aquator) being used to facilitate the release of the wet nanocomposite sheets. The sheets, still attached to the blotter and the auxiliary wire fabric, were dried on a drum having a surface temperature of ca $60{ }^{\circ} \mathrm{C}$. The blotter and auxiliary wire fabrics were removed, and the sheets were conditioned (SCAN-P 2:75, temperature $23 \pm 1{ }^{\circ} \mathrm{C}$, relative humidity $50 \pm 2 \%$ ).

When the furnish for the composite sheets was prepared, the required amounts of PCC slurry, wet microfibrillated cellulose and tap water were weighed and mixed. High intensity mixing was applied with a Diaf dissolver and low intensity mixing with an overhead stirrer. The amount of anionic polyelectrolyte (aPAM, Fennopol A305, Kemira, $-2.5 \mathrm{mekv} / \mathrm{g}$ and molecular weight above $15 \bullet 10^{6} \mathrm{~g} / \mathrm{mol}$ ) was $2 \mathrm{wt} \%$ based on furnish solids.

The conditioned sheets were calendered (DT Laboratory Sheet Calender, Finland) with a line load of 40 $\mathrm{kN} / \mathrm{m}$ in nip imitating a supercalendar nip structure. The soft roll was unheated while the hard roll was heated to $120{ }^{\circ} \mathrm{C}$. Three levels of calendering were applied by changing the number of nips: 1,3 and 10 . The wire side was in contact with the soft roll during all the nips, and this side was subsequently tested.

\section{Methods}

Material characterization

\section{Scanning electron microscopy}

A Hitachi SU3500 with Hitachi secondary electron (SE) detector and backscatter electron (BS) detector used in composition mode (BSE-comp) was used to capture images of the samples. When the BSE-comp was used, the microscope was operated in the variable pressure mode.

The PCC samples were imaged with an SE detector (sputter-gold on sample, $5 \mathrm{kV}$ ) for visual assessment and with BSE detector $(10 \mathrm{kV}$, ca. $5 \mathrm{~mm}$ working distance, $40 \mathrm{~Pa}$ ) for static image analysis software. The sheets were imaged on top with BSE-comp, $30 \mathrm{~Pa}$, and a working distance of approximately $10 \mathrm{~mm}$. Cross-section images of composite sheets were captured from samples cast in acrylic resin (Stuers ClaroCit), using BSE-comp, $60 \mathrm{~Pa}$, and a working distance of approximately $5 \mathrm{~mm}$.

\section{Particle size and shape measurements}

The particle size distribution (PSD) of the PCC was determined on the dispersion using a laser diffraction particle size analyzer (Mastersizer 3000, Malvern), and on the dried sample using static image analysis (Morphologi G3, Malvern) of a series of SEM images. The static image analysis was used to determine particle shape factors of PCC.

\section{Charge density (Cationic demand)}

The charge density of re-dispersed sheets was measured using a cationic demand titration (PCD 02, BTG Mütek GmbH and Mettler DL25, GWB for titrant dosing) using a direct method similar to that presented by Junka et al (2013). The sample dispersing procedure was modified due to solid sample, and the obtained sample slurry was measured using higher solids content $(4,4.5$ and $5 \mathrm{~g} / \mathrm{l})$ previously found to be well in the plateau area of the PCD titration for the samples. The titrants used were solutions of PDADMAC $(0.5 \mathrm{mN}, \mathrm{M}=107,000 \mathrm{~g} / \mathrm{mol}, \mathrm{BTG})$ and polyethene sodium sulfonate (PES-Na, 1.0 and 0.5 $\mathrm{mN} \mathrm{M}=19,100 \mathrm{~g} / \mathrm{mol}$, BTG). The matrix was $0.01 \mathrm{M} \mathrm{NaCl}$ solution, and the $\mathrm{pH}$ of the samples 
was 9.1 to 9.3 to ensure that none of the samples would require $\mathrm{pH}$ control using an acidic compound. The $\mathrm{pH}$ was controlled using a $\mathrm{NaOH}$ solution $(0.15 \mathrm{M}$ and $0.04 \mathrm{M}, \mathrm{VWR}$, purity $99.4 \%$ ).

The sheets were re-dispersed as follows: the sheets were torn to ca. $1 \mathrm{~cm} \times 1 \mathrm{~cm}$ pieces by hand and soaked in $0.01 \mathrm{M} \mathrm{NaCl}$ solution overnight. The sheets were then disintegrated by manual mixing to ca. $1 \mathrm{wt} \%$ solids content, followed by further mixing and homogenizating with a disperser (Ultra Turrax T25 Digital, IKA) for $5 \mathrm{~min}$ at $10000 \mathrm{rpm}$.

\section{Zeta potential}

The electrophoretic mobility of the re-dispersed samples (see Charge density) was measured using Zetasizer ZS Nano (Malvern Instruments Ltd, UK) equipped with helium-neon gas laser (HeNe laser, $633 \mathrm{~nm}$ ) at a temperature of $25^{\circ} \mathrm{C}$. The zeta potential was calculated using the Henry equation with the Smoluchowski approximation. The $\mathrm{pH}$ values were adjusted to $9.2( \pm 0.1)$ with $\mathrm{NaOH}$. The anionic charge behavior of the MFC was determined by electrophoretic measurement in deionized water and of $\mathrm{pH} 9$.

The PCC dispersion was measured under the same conditions but using $\mathrm{HCl}(0.05 \mathrm{M})$ for $\mathrm{pH}$ control. The solids content was ca. $0.3 \mathrm{wt} \%$.

\section{Contact angle, liquid absorption and surface energy measurements}

The apparent contact angles (CA) were determined using distilled water (DI), 99\% diiodomethane $\mathrm{CH}_{2} \mathrm{I}_{2}$ (DIM, Alfa Aesar) and 99.8\% ethylene glycol 1,2ethanediol (EG, VWR Prolabo). The droplet volume was $1 \mu \mathrm{l}$, and the contact angle was recorded with a $420 \mathrm{~Hz}$ camera (Basler A602F-2 with Navitar optics) immediately after the drop contacted the surface. The contact angle and the drop volume were measured repeatedly from initial contact to $10 \mathrm{~s}$ or complete wetting. Digital images were analyzed with the OneAttension image tool. The baseline was set manually for all the samples.

\section{Sheet properties}

Sheet properties of the composite sheets were measured after conditioning the samples at $23{ }^{\circ} \mathrm{C}$ and $50 \%$
RH. The grammage (SCAN-P6:75), brightness (SCAN-P 3:93), opacity (SCAN-P 8:93) and ash content (SCAN-C 6:62) were measured before calendaring. The thickness and density (SCAN-P 7:96), Bendtsen porosity (SCAN-P 85:02) and PPS-roughness (SCAN-P 76:95) were measured on both calendered and uncalendered samples.

\section{Ink absorption and spreading and printing tests}

Liquid absorption and spreading behavior on the sheet surfaces were assessed by inkjet printing tests. Samples were conditioned at $23{ }^{\circ} \mathrm{C}$ and $50 \%$ RH before being printed on a Lomond Evojet Memjet printer, using dye-based anionically charged ink. The print density was measured with a spectrophotometer (Xrite SpectroEye), and ink bleeding was determined with a pocket microscope (DPM 100, Fibro System AB) from the raggedness of black and red lines printed on white with a yellow boundary based on the ISO/ IEC 13660:2001 standard.

\section{Anionic liquid absorption assessment: ink staining and stain analysis}

Magenta ink dots $(6.25 \%$ coverage on the print) were studied using static image analysis (Morphologi G3, Malvern). The printed sample area was cut and placed on two $\left(70 \mathrm{~g} / \mathrm{m}^{2}\right)$ pieces of copy paper between two microscope glasses to provide a smooth, imageable surface. The copy paper beneath the sample was used only to increase the opacity of the imaged area and to eliminate most "dark spots" caused by less opaque areas. The lower size cutoff was CE diameter $10 \mu \mathrm{m}$ and the particle data were checked manually to eliminate objects other than ink dots. Interconnected dots were also removed. The numerical data was thereafter expanded with visual analysis of microscope images of the magenta ink dots.

\section{Results}

PCC synthesis and characterization

The conditions selected for the synthesis of the precipitated calcium carbonate (PCC) yielded elongated "cigar-shaped" particles and aggregates. Circle equivalent (CE) diameter and the elongation of the 


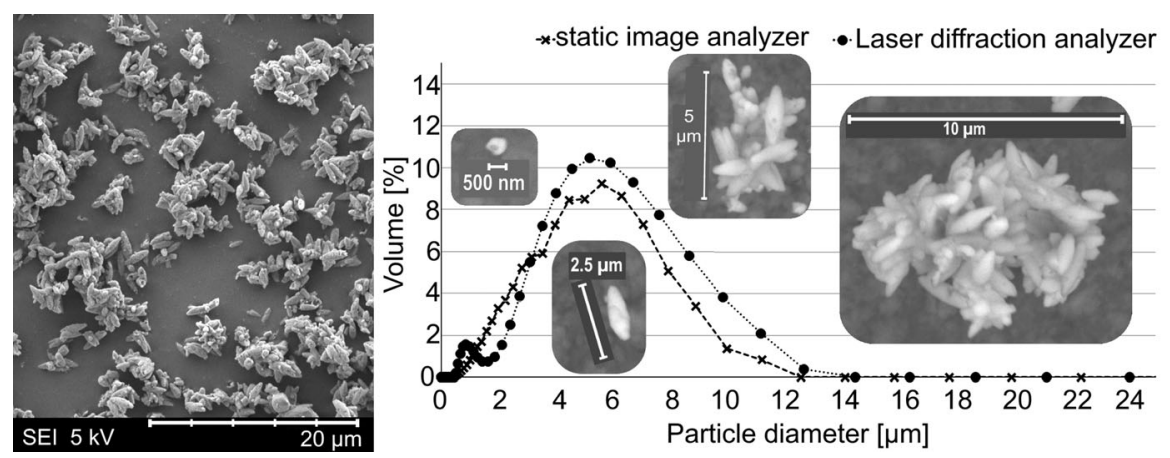

Fig. 2 SEM image of the cationically charged PCC and PCC particle size distribution. Note the linear scales. The close-ups show small rounded particles (circularity close to 1), a typical cigar-shaped single particle and two aggregates of different sizes

PCC particles increased initially with increasing particle size, which was associated with the growth of the single particles. Larger clusters of PCC crystals were less elongated and more circular. Typical particles with low elongation (close to 0) and high circularity (above 0.98 ) were single crystals, whereas particles with high elongation (above 0.74) were typically single crystals which had grown into a cigar shape. Aggregation typically resulted in particles and clusters of medium elongation and circularity. Examples of the particle types are shown in Fig. 2.

The CE diameter was found to be in good agreement with data obtained from laser diffraction particle size and size distribution measurements (result presented in Fig. 2). 50\% cut off diameter was $5.2 \mu \mathrm{m}$ according to laser diffraction analysis and $4.9 \mu \mathrm{m}$ according to static image analysis.

The presence of the cationic PDADMAC during precipitation gave cationic PCC, which was confirmed from the zeta potential measurements. The $\zeta$-potential of the PCC suspension was $+31.7 \mathrm{mV}$ in $0.01 \mathrm{M}$ $\mathrm{NaCl}$ solution ( $\mathrm{pH} 9.1)$.

Properties of composite sheet containing MFC and PCC

The cationic PCC particles and microfibrillated cellulose (MFC) were further used to prepare composite sheets, which were densified to different extent using a laboratory calender. Properties before and after calendering are listed in Tables 1 and 2, respectively. PCC retention, calculated assuming 100\% fiber retention, was between 88 and $94 \%$ in all cases. As the $100 \mu \mathrm{m}$ openings of the auxiliary wire were roughly twenty times the $50 \%$ cut off size of PCC particles, the high level of retention was primarily associated with floc formation.

The brightness and opacity of uncalendered samples were found to increase with increasing ash content, even though the measured grammage of the heavily filled sheets was significantly lower than that of the lightly filled sheets, affecting negatively to opacity. Increasing level of calendering increased the sheet density and decreased sheet thickness, although minor irregularities were observed in the trend (see Table 2). This was associated with variation within the sheets and calendering pressure. Therefore, calendering results were primarily described in terms of sheet density. Increase in calendaring also resulted in decrease in porosity and PPS roughness. The PCCto-MFC ratio and the use of flocculating agent had a great influence on the calendering result. With a greater degree of densification, the porosity and PPS roughness were reduced with increasing PCC-to-MFC ratio. The use of a flocculation aid gave a more porous and rough sheet, presumably to do a greater tendency to form or larger aggregates and MFC-PCC flocs. Sheets made without the flocculating agent exhibited a lower particle adhesion, i.e. increased tendency to dust.

SEM imaging of composite sheets

When the PCC-to-MFC ratio in the samples was increased, an uneven pigment distribution pattern at the higher and lower PCC concentration on the composite sheet surface became obvious. In the "large scale" of hundreds of microns it was attributed to open and closed areas of the auxiliary wire, as shown in Fig. 3. The changing PCC concentration on 
Table 1 Sheet properties of the samples measured before calendering

\begin{tabular}{llllll}
\hline & PCC-to-MFC & Grammage $\left(\mathrm{g} / \mathrm{m}^{2}\right)$ & Ash content $(\%)$ & Brightness, D65 $(\%)$ & Opacity $(\%)$ \\
\hline HI-mix & 1 -to-2 & 96 & 29.7 & 83.3 & 95.5 \\
& 1 -to-1 & 90 & 45.5 & 84.3 & 98.2 \\
& 2 -to-1 & 77 & 61.5 & 86.5 & 97.5 \\
Flocc & $1-$-to-2 & 103.5 & 29.3 & 81.1 & 97.3 \\
& $1-$-to-1 & 96 & 45.5 & 82.2 & 97.5 \\
& 2-to-1 & 88 & 62.8 & 87.7 & 98.4 \\
\hline
\end{tabular}

Table 2 Properties of calendered sheets

\begin{tabular}{|c|c|c|c|c|c|c|}
\hline & PCC-to-MFC & Nips & Thickness $(\mu \mathrm{m})$ & Density $\left(\mathrm{kg} / \mathrm{m}^{3)}\right.$ & PPS roughness $(\mu \mathrm{m})$ & Porosity ( $\mu \mathrm{mPas})$ \\
\hline \multirow[t]{12}{*}{ HI-mix } & \multirow[t]{4}{*}{1 -to-2 } & 0 & 134 & 679 & 6.6 & 14 \\
\hline & & 1 & 91 & 948 & 3.0 & 0.40 \\
\hline & & 3 & 81 & 1034 & 2.0 & 0.30 \\
\hline & & 10 & 94 & 1053 & 1.8 & 0.40 \\
\hline & \multirow[t]{4}{*}{1 -to-1 } & 0 & 144 & 611 & 5.2 & 23 \\
\hline & & 1 & 85 & 997 & 1.8 & 1.0 \\
\hline & & 3 & 78 & 1061 & 1.4 & 0.60 \\
\hline & & 10 & 77 & 1059 & 1.3 & 0.40 \\
\hline & \multirow[t]{4}{*}{ 2-to-1 } & 0 & 150 & 479 & 7.5 & 61 \\
\hline & & 1 & 76 & 1013 & 1.6 & 7.2 \\
\hline & & 3 & 74 & 1068 & 1.3 & 6.3 \\
\hline & & 10 & 58 & 1099 & 0.9 & 8.2 \\
\hline \multirow[t]{12}{*}{ Flocc } & \multirow[t]{4}{*}{ 1-to-2 } & 0 & 138 & 639 & 7.0 & 33 \\
\hline & & 1 & 89 & 992 & 3.7 & 0.20 \\
\hline & & 3 & 103 & 886 & 2.2 & 0.20 \\
\hline & & 10 & 92 & 1030 & 2.0 & 0.10 \\
\hline & \multirow[t]{4}{*}{ 1-to-1 } & 0 & 157 & 554 & 7.3 & 45 \\
\hline & & 1 & 88 & 932 & 2.6 & 2.3 \\
\hline & & 3 & 90 & 1025 & 1.4 & 0.70 \\
\hline & & 10 & 93 & 944 & 1.5 & 1.9 \\
\hline & \multirow[t]{4}{*}{ 2-to-1 } & 0 & 155 & 575 & 5.5 & 61 \\
\hline & & 1 & 92 & 981 & 1.7 & 12 \\
\hline & & 3 & 90 & 978 & 1.7 & 13 \\
\hline & & 10 & 80 & 1053 & 1.2 & 13 \\
\hline
\end{tabular}

the sheet surface was especially evident in uncalendered high ash-content sheets made without flocculating agent. The flocculating agent created surfaces with a higher PCC concentration in "small-scale" of tens of microns, ascribed to the formation of PCCrich flocs.
Calendering of the composite sheets was found to affect the lateral distribution of the PCC. Without flocculant, however, calendering made the PCC distribution more even in the large-scale region of hundreds of microns, probably because due to the transferred wire image was lost during the 

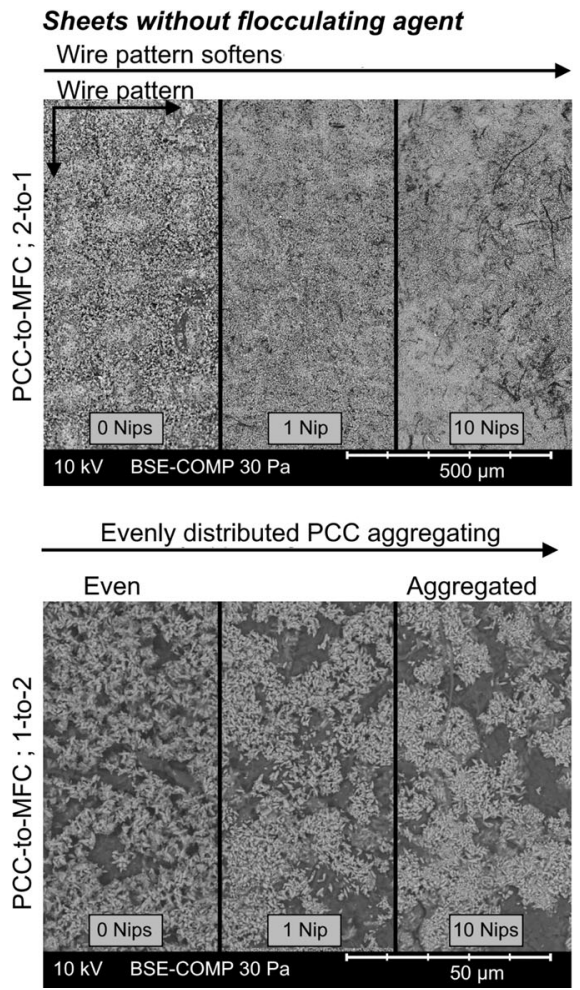

Fig. 3 SEM images of the wire side of the calendered samples. The " 0 nip" samples show the sample surface after wet-laying and drying but before calendering, whereas 1 nip and 10 nips show the PCC distribution on the sheet surfaces after different

\section{Sheets with the flocculating agent}

Wire pattern hardly visible No obvious softening of the pattern

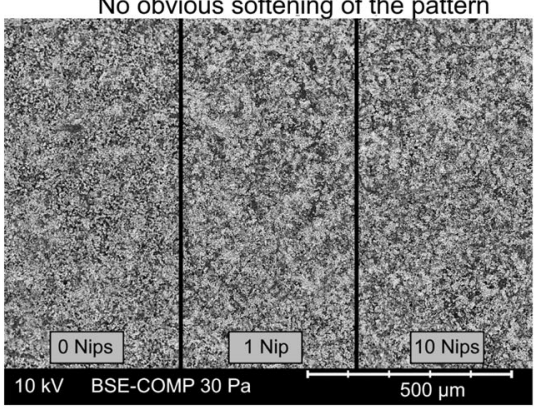

Mildly aggregated PCC aggregating further

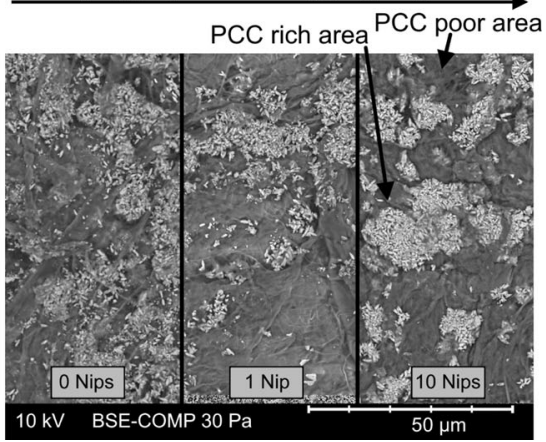

levels of calendering. Note the different PCC-to-MFC ratios (columns) and scale bars (rows). More images on the wire side are presented as Online Resource 1

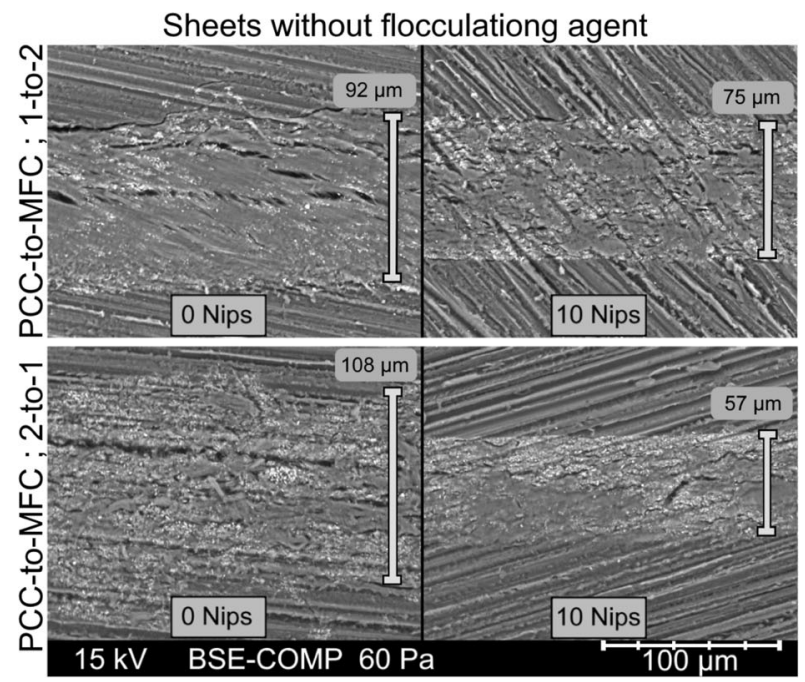

Fig. 4 SEM images of cross-cut samples with different PCC-toMFC levels (upper and lower rows). Wire side (i.e. printed side) faces up in the images. The left-hand side shows sheets prepared

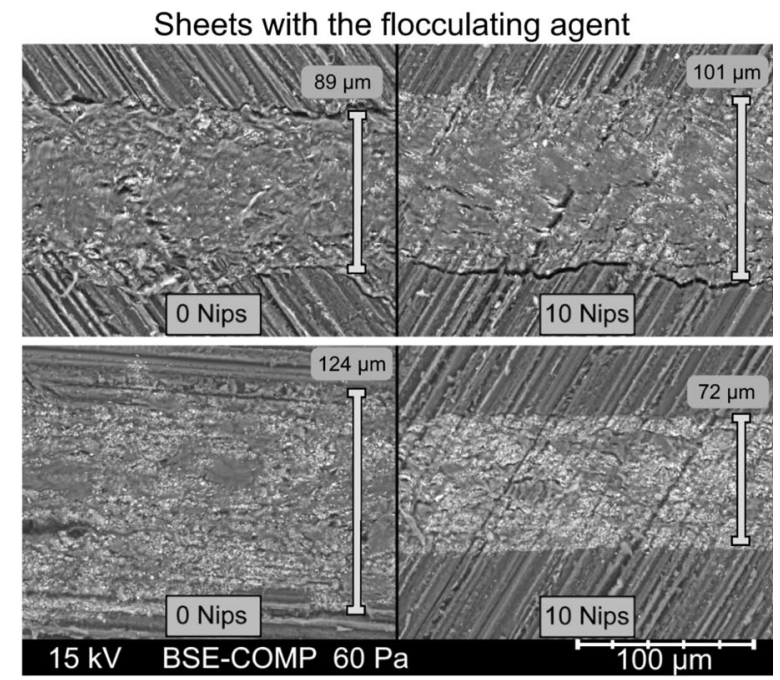

without flocculating agent, and the right-hand side with flocculating agent. More cross-cut sample images are presented as Online Resource 2 


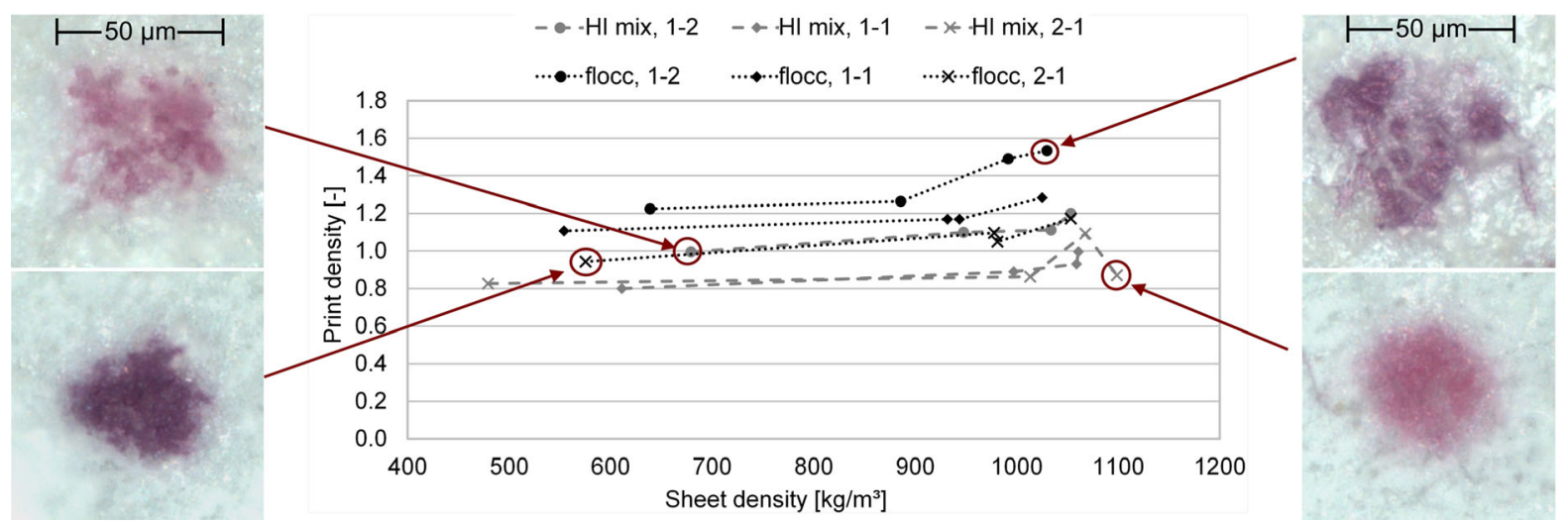

Fig. 5 Print density plotted against composite sheet density and droplet (magenta) behavior on the sheets. "HI mix" refers to high intensity mixing, "flocc" to use the of aPAM as a flocculating agent. The legend values indicate the PCC-to-MFC ratio in the sheet. The dots on the sheets made using the

calendaring. The enhanced homogeneity and filler distribution effect was associated with material flow towards and on the surface during the calendering. This was not observed when the flocculating agent was present.

The flocculating agent appeared to stabilize the sheets against movement of PCC on the scale of tens of microns. On this scale, the sheets made without flocculating agent showed a gradual aggregation of PCC, which was not evident in the samples with flocculating agent, see Fig. 3.

The cross-section images (Fig. 4) also show differences in PCC distribution within sheets depending on flocculant had a darker color, and the color was less even with more spreading when the composite sheets contained more MFC. The scale bars apply to all microscope images. The sheet density was altered with calendering $(0,1,3$ and 10 nips) and the sheets were printed on the wire side

the level of calendering. There was difference between the uncalendared samples with and without the flocculant, but with increasing calendering nips the PCC in the sample made without flocculating agent concentrated on the wire side of the sheet (i.e. the side in contact with the soft roll during calendering). Thus, calendering increased the amount of PCC on the sheet surfaces of these samples. This effect was not seen in sheets made with the flocculating agent.

No obvious differences linked with the presence of the flocculation agent were seen in the cross-section images, but an increase in the PCC-to-MFC ratio was seen to improve the smoothing and compressibility of

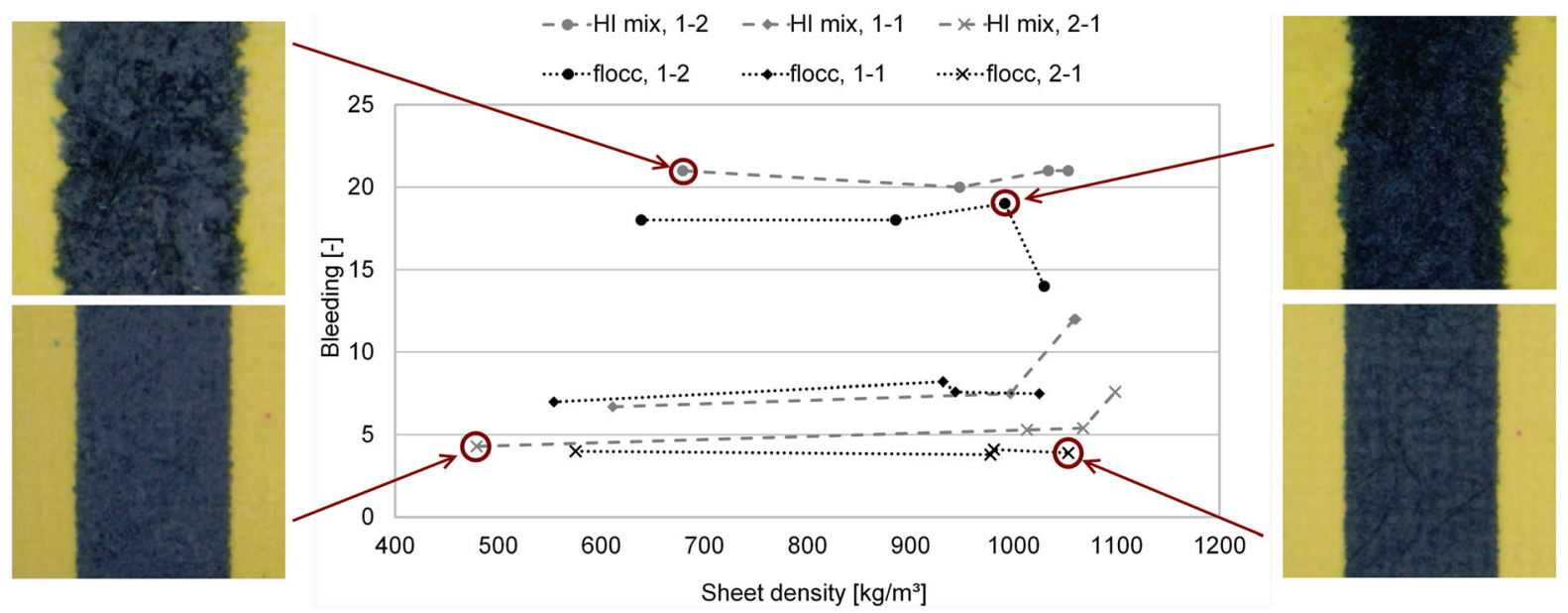

Fig. 6 Bleeding of black ink plotted against sheet density, for different degrees of calendering (0, 1, 3 and 10 nips). "HI mix" refers to high intensity mixing, and "flocc" to the use of aPAM as a flocculating agent. The legend values indicate the PCC-toMFC ratio in the composite sheet. Sheets were printed on the wire side 
Table 3 The average contact angles measured between 0 and $0.12 \mathrm{~s}\left(\mathrm{t}_{1}\right)$ and between $1.92-2.07 \mathrm{~s}\left(\mathrm{t}_{2}\right)$ after contact, and the corresponding drop volume

\begin{tabular}{|c|c|c|c|c|c|c|c|c|c|c|c|c|c|c|}
\hline & \multirow[t]{3}{*}{ PCC-to-MFC } & \multirow[t]{3}{*}{ Nips } & \multicolumn{4}{|l|}{ EG } & \multicolumn{4}{|c|}{ DIM } & \multicolumn{4}{|l|}{ DI } \\
\hline & & & \multicolumn{2}{|c|}{$\mathrm{CA}$} & \multicolumn{2}{|c|}{ Drop vol } & \multicolumn{2}{|c|}{$\mathrm{CA}$} & \multicolumn{2}{|c|}{ Drop vol } & \multicolumn{2}{|l|}{$\mathrm{CA}$} & \multicolumn{2}{|c|}{ Drop vol } \\
\hline & & & $\mathrm{t}_{1}$ & $\mathrm{t}_{2}$ & $\mathrm{t}_{1}$ & $\mathrm{t}_{2}$ & $\mathrm{t}_{1}$ & $t_{2}$ & $t_{1}$ & $\mathrm{t}_{2}$ & $\mathrm{t}_{1}$ & $t_{2}$ & $t_{1}$ & $\mathrm{t}_{2}$ \\
\hline \multirow[t]{12}{*}{ HI-mix } & \multirow[t]{4}{*}{1 -to-2 } & 0 & 35 & & 0.47 & & 18 & & & & 20 & & 0.37 & 0.27 \\
\hline & & 1 & 31 & & 0.93 & & 24 & 13 & 0.98 & 0.92 & 26 & 19 & 0.97 & \\
\hline & & 3 & 32 & 16 & 1.38 & 0.92 & 25 & 18 & 0.66 & 0.63 & 42 & 32 & 1.40 & 0.85 \\
\hline & & 10 & 37 & 18 & 0.92 & 1.03 & 27 & 23 & 1.00 & 0.84 & 53 & 47 & 1.12 & \\
\hline & \multirow[t]{4}{*}{1 -to-1 } & 0 & 38 & & 0.57 & & 19 & & 0.64 & & 21 & & 0.25 & \\
\hline & & 1 & 33 & & 0.76 & & 20 & 7 & 0.65 & 0.25 & 31 & & 0.62 & \\
\hline & & 3 & 35 & 21 & 0.84 & 0.65 & 27 & 22 & 1.17 & 1.01 & 45 & 37 & 1.00 & 0.78 \\
\hline & & 10 & 38 & 24 & 0.89 & 0.80 & 25 & 20 & 0.62 & 0.60 & 56 & 46 & 1.39 & \\
\hline & \multirow[t]{4}{*}{ 2-to-1 } & 0 & 17 & & 0.71 & & 16 & & 0.53 & & 23 & & 0.51 & \\
\hline & & 1 & 20 & 20 & 0.92 & & 15 & & 0.20 & & 37 & 29 & 0.87 & \\
\hline & & 3 & 34 & 21 & 0.95 & 0.65 & 22 & 17 & 0.78 & 0.70 & 37 & & 0.96 & \\
\hline & & 10 & 36 & 25 & 1.07 & 0.85 & 20 & 11 & 0.43 & & 46 & & 0.14 & \\
\hline \multirow[t]{12}{*}{ Flocc } & \multirow[t]{4}{*}{ 1-to-2 } & 0 & 35 & 17 & 1.56 & 0.59 & 24 & & 0.46 & & 29 & & 0.49 & \\
\hline & & 1 & 37 & 23 & 1.01 & 0.96 & 30 & 28 & 0.64 & 0.62 & 60 & 40 & 0.88 & 0.96 \\
\hline & & 3 & 35 & 18 & 0.92 & 0.70 & 23 & 21 & 0.66 & 0.49 & 48 & 40 & 1.72 & \\
\hline & & 10 & 35 & 21 & 1.04 & 0.93 & 33 & 32 & 0.78 & 0.74 & 48 & & 1.04 & 1.04 \\
\hline & \multirow[t]{4}{*}{ 1-to-1 } & 0 & 27 & & 0.52 & & 16 & & 0.29 & & 18 & & 0.79 & \\
\hline & & 1 & 33 & 15 & 0.81 & 0.57 & 33 & 27 & 0.70 & 0.59 & 36 & & 1.01 & \\
\hline & & 3 & 35 & 22 & 0.96 & 0.63 & 25 & 22 & 0.79 & 0.66 & 50 & 35 & 0.98 & 0.34 \\
\hline & & 10 & 39 & 23 & 0.74 & 0.52 & 27 & 22 & 0.64 & 0.48 & 52 & & 1.88 & 0.75 \\
\hline & \multirow[t]{4}{*}{ 2-to-1 } & 0 & 27 & & 0.67 & & 15 & & 0.67 & & 28 & & 0.52 & \\
\hline & & 1 & 31 & 22 & 0.98 & 0.81 & 21 & 13 & 0.98 & 0.27 & 39 & 15 & 1.00 & \\
\hline & & 3 & 33 & 18 & 0.77 & 0.76 & 17 & 13 & 0.77 & & 40 & 40 & 0.73 & \\
\hline & & 10 & 34 & 25 & 0.87 & 0.71 & 23 & 17 & 0.87 & 0.65 & 45 & 15 & 0.80 & \\
\hline
\end{tabular}

The missing data indicates failed measurement, i.e. drop absorption or excessive sample swelling. The contact angles were measured on the wire side

the sheets, in good agreement with the measured PPS roughness values.

Printing test results

\section{Print density}

The interaction between the ink and composite sheets and especially ink hold-out were assessed by determining the print density. Figure 5 shows that, although the absolute values differed, the print densities of the $100 \%$ coverage black and magenta inks were affected similarly. The greatest difference was obtained by changing the chemical composition of composite sheet: increasing the proportion MFC in the sheets increased the print density, as did the use of the flocculating aid. Calendering (observed as increasing sheet density and decreasing porosity and PPS roughness) increased the print density the effect being greater when the flocculating agent was used.

\section{Ink bleeding}

The ink levelling and spreading behavior was investigated by measuring the bleeding tendency of black ink on yellow ink. Neither of the porosity nor the roughness was found to affect the bleeding, see Fig. 6. Sheets made without flocculating aid appeared more 


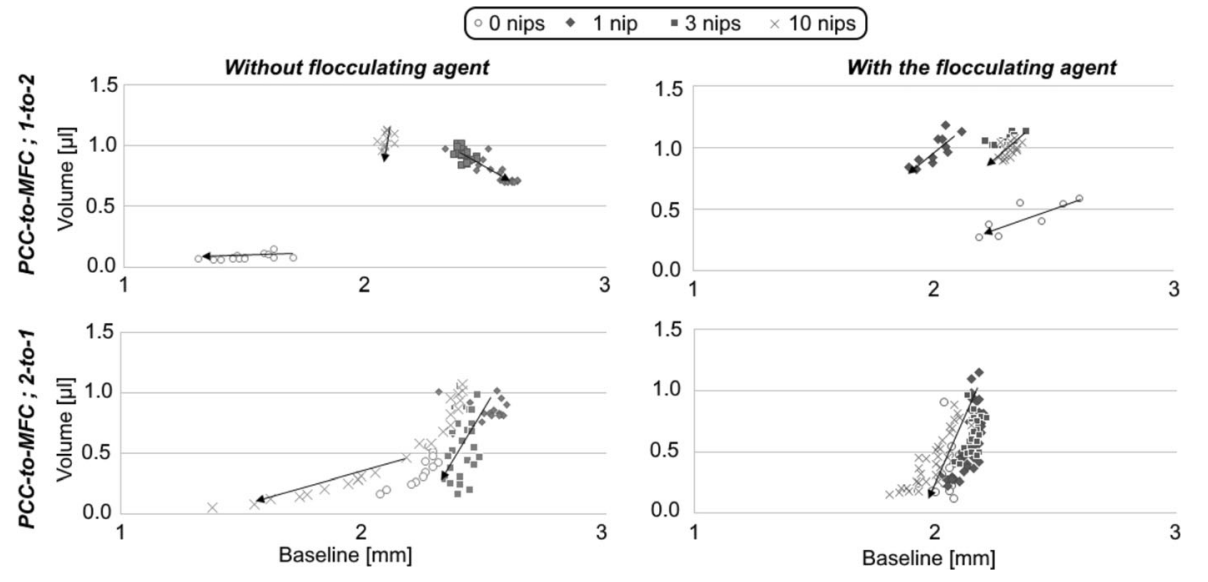

Fig. 7 Spreading of water droplets on the composite sheets (wire side). The volume is the calculated volume of the droplet, and the baseline is the measured width of the droplet. The arrows

prone to black ink bleeding when calendered to a high density, but no relation between bleeding and sheet density was seen for magenta ink.

Liquid absorption and absorption visualization

\section{Contact angle and absorption}

Liquid absorption into samples was fast, leading to a rapid change in contact angle (CA) at the beginning of measurement and also in sample swelling, as seen in Table 3. The values given are an average between $0.0-0.12 \mathrm{~s}\left(\mathrm{t}_{1}\right)$ and an average between 1.92-2.07 s ( $\left.\mathrm{t}_{2}\right)$.

The contact angle and drop absorption tests showed that calendering led to surface closure, seen as slower absorption. The CA of all the test liquids was found to be affected more by calendering than by the PCC-toMFC ratio or the use of flocculating agent, especially at short drop contact times.

The spreading of the water droplets is shown in Fig. 7. At the low PCC-to-MFC ratio of 1-to-2, the water droplet spread on the surface. With flocculant, a more water repellent surface was obtained, as less spreading occurred. The drop was absorbed more rapidly into the uncalendered sample. At higher calendering levels, the droplet remained on the surface, particularly when flocculant was used.

\section{Static image analysis of ink dots}

The average size and shape of the magenta ink dots shared only minor trends in CE diameter, circularity, show the time, i.e. the direction of change. Note the different PCC-to-MFC ratios (rows) and the use of the flocculating aid (columns)

elongation and convexity. When averages for the different calendering levels were calculated, the $\mathrm{CE}$ diameter and elongation were found to decrease with increasing PCC content, and the circularity and convexity increased. The average values (see Table 4) did not however show any correlation with the composite sheet properties, nor with the print density or bleeding.

Distributions (not shown here) of the measured parameters were found to be affected more by the PCC-to-MFC ratio. The distribution of CE diameter narrowed and its peak shifted to a lower value, corresponding with the slight decrease in average CE diameter with increasing ash content. The elongation distribution became more narrow and also shifted to a lower value, showing that the difference between dot length and width became less. The distribution width in circularity was less affected, but the peak shifted to indicate more circular dots. The convexity distribution narrowed considerably. The results were in good agreement with the visual assessment of the dots (shown in Fig. 5). Microscope images show that the dots printed on the sheets containing flocculating agent appeared darker.

\section{Charge density and $\zeta$-potential}

The $\zeta$-potential and charge density determined for the re-dispersed samples showed that most of the samples had a cationic charge. Only when the PCC-to-MFC ratio was 1-to-2 did both methods suggest that the samples were slightly anionic. The results are shown 
Table 4 The average CE diameters, circularities, convexities and elongations of ink dots. The sheets were printed on the wire side

\begin{tabular}{|c|c|c|c|c|c|c|c|}
\hline & $\begin{array}{l}\text { PCC-to- } \\
\text { MFC }\end{array}$ & Nips & $\begin{array}{l}\text { Amount of particles } \\
(-)\end{array}$ & $\begin{array}{l}\text { CE Diameter Mean } \\
(\mu \mathrm{m})\end{array}$ & $\begin{array}{l}\text { Circularity } \\
\text { mean }\end{array}$ & $\begin{array}{l}\text { Convexity } \\
\text { mean }\end{array}$ & $\begin{array}{l}\text { Elongation } \\
\text { mean }\end{array}$ \\
\hline \multirow{12}{*}{$\begin{array}{l}\text { HI- } \\
\text { mix }\end{array}$} & \multirow[t]{4}{*}{$1-2$} & 0 & 15,347 & 42.9 & 0.36 & 0.86 & 0.20 \\
\hline & & 1 & 11,846 & 39.1 & 0.38 & 0.87 & 0.21 \\
\hline & & 3 & 14,377 & 48.4 & 0.36 & 0.91 & 0.18 \\
\hline & & 10 & 19,061 & 46.7 & 0.40 & 0.85 & 0.21 \\
\hline & \multirow[t]{4}{*}{$1-1$} & 0 & 8455 & 38.3 & 0.56 & 0.92 & 0.14 \\
\hline & & 1 & 8290 & 39.2 & 0.55 & 0.91 & 0.14 \\
\hline & & 3 & 15,293 & 43.4 & 0.40 & 0.90 & 0.14 \\
\hline & & 10 & 11,391 & 39.9 & 0.54 & 0.90 & 0.12 \\
\hline & \multirow[t]{4}{*}{$2-1$} & 0 & 13,946 & 34.3 & 0.50 & 0.92 & 0.16 \\
\hline & & 1 & 10,766 & 38.0 & 0.48 & 0.93 & 0.12 \\
\hline & & 3 & 11,105 & 47.6 & 0.38 & 0.89 & 0.18 \\
\hline & & 10 & 11,480 & 46.9 & 0.46 & 0.93 & 0.13 \\
\hline \multirow[t]{11}{*}{ Flocc } & \multirow[t]{3}{*}{$1-2$} & 0 & 10,281 & 45.4 & 0.33 & 0.88 & 0.22 \\
\hline & & 1 & 13,716 & 43.1 & 0.30 & 0.77 & 0.28 \\
\hline & & 3 & 15,360 & 47.3 & 0.33 & 0.84 & 0.23 \\
\hline & \multirow[t]{4}{*}{$1-1$} & 0 & 9329 & 43.5 & 0.34 & 0.86 & 0.23 \\
\hline & & 1 & 6453 & 49.2 & 0.32 & 0.87 & 0.19 \\
\hline & & 3 & 12,644 & 47.8 & 0.36 & 0.86 & 0.18 \\
\hline & & 10 & 11,103 & 48.5 & 0.33 & 0.86 & 0.20 \\
\hline & \multirow[t]{4}{*}{$2-1$} & 0 & 14,932 & 42.2 & 0.49 & 0.93 & 0.14 \\
\hline & & 1 & 12,962 & 41.9 & 0.54 & 0.94 & 0.13 \\
\hline & & 3 & 14,300 & 43.1 & 0.45 & 0.92 & 0.13 \\
\hline & & 10 & 12,815 & 41.7 & 0.51 & 0.93 & 0.13 \\
\hline
\end{tabular}

in numerical form in Table 5. The two methods were found to yield curves of similar shapes, after scaling to the unity, see Fig. 8.

The use of flocculant was found to decrease both the charge density and $\zeta$-potential. This was expected, as the flocculant was anionic and likely to partially neutralize the cationic charges of PCC and probably partially be adsorbed on the fiber.

A plot of print density against to $\zeta$-potential or charge density of the re-dispersed composite sheet samples was almost linear and independent of the flocculating agent. Figure 9 shows that the print density was more affected by the flocculant than the charge density, indicating that anionic-cationic interactions alone cannot explain the differences in print quality observed between the series prepared with and without flocculant.

\section{Discussion}

Filler migration during calendering and preforming of flocs

The observed filler migration caused by the flocculating agent was strongly associated with the floc structure. The $\zeta$-potential and charge density suggested beneficial conditions for floc formation, but the floc forming mechanism can be expected to differ between the sheets made with and without flocculating agent. While fillers and fines are flocculated and fixed mainly via chemical interactions (Beghello 1998; Yan 2009), the fibrillar structure of MFC is expected to lead to more mechanical flocculation (Sorvari et al. 2014). In the case of PCC and nanofibrillated cellulose, mechanical interlocking and anionic-cationic interaction have been reported by Korhonen and Laine 
(2014). Flocculation by the fibrils was claimed to be reversible (Korhonen and Laine 2014), and it is often linked with patch flocculation and soft flocs (Unbehend and Britt 1982).

The presence of soft flocs and reversible flocculation due to the mechanical tangling of fiber and the ionic interaction of the cationic PCC and fibers was not studied in this work, but it is probable that reversible flocculation and association of flocs occur. High-shear mixing was applied to the furnish, and this was expected to disrupt any soft floc formation caused by mechanical entanglement.

When the flocculating agent was added, the formation of hard flocs was expected, and subsequent addition of MFC was expected to alter the stability of the PCC flocs, as aPAM of high molar mass is known to stabilize MFC against floc formation (Korhonen et al. 2014). This approach, resembling the dual component retention systems used in papermaking described e.g. by Aloi and Trsksak (1998), was likely to initiate flocculation of PCC and MFC via "patch and bridge". Dual polymer systems are known produce hard flocs, as a result of strong bonding between the particles (Unbehend and Britt 1982).

The more strongly bonded PCC in the sheets was probably less free to cause material flow and provide loose particles to be re-attached during the calendering process. The filler distribution in both the lateral and z-direction were less affected by the use of the flocculating agent, and dusting of the sheets decreased. The use of flocculants has also been reported to lead to a more even filler distribution through the sheet, as a result of filler adsorption onto the fibers (Cho et al. 2006).

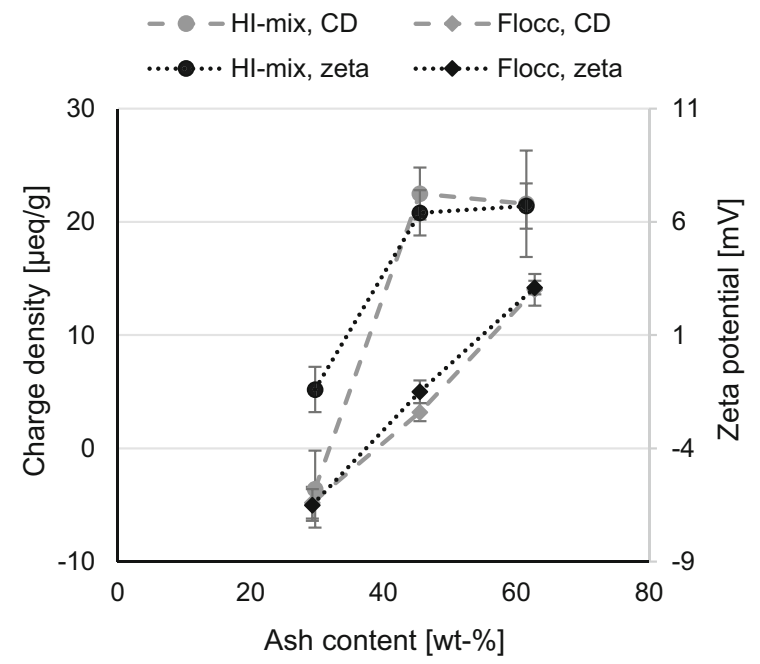

Fig. 8 Charge density ("CD") and $\zeta$-potential ("zeta") curves of the re-dispersed composite sheets. The bars show confidence values $(95 \%)$

Ink absorption and colorant fixation mechanism

The composite sheets showed a fairly rapid absorption of water (i.e. the dye solvent), which is desirable for effective colorant retention and rapid ink immobilization (Kettle et al. 2010). The development of print density, bleeding, drop shapes and drop absorption results in the present work supported the observation that the ink was more prone to be absorbed by PCCrich structures than into MFC, which emphasize the role of molecular interaction vs. microporosity.

For efficient colorant fixation, cationic modified surfaces typically perform well with anionic inks. Cationic groups (including $\mathrm{Ca}^{2+}$ ) on the substrate are

Table 5 Charge density and $\zeta$-potential of re-dispersed, non-printed sheets

\begin{tabular}{|c|c|c|c|c|c|c|c|c|}
\hline & & \multicolumn{3}{|l|}{ Charge density } & \multicolumn{4}{|l|}{$\zeta$-potential } \\
\hline & & $\begin{array}{l}\text { Charge density } \\
(\mu \mathrm{eq} / \mathrm{g})\end{array}$ & $\begin{array}{l}\text { Confidence value } \\
(95 \%)\end{array}$ & $\begin{array}{l}\mathrm{pH} \\
(-)\end{array}$ & $\begin{array}{l}\zeta \text {-potential } \\
(\mathrm{mV})\end{array}$ & $\begin{array}{l}\text { Confidence value } \\
(95 \%)\end{array}$ & $\begin{array}{l}\mathrm{pH} \\
(-)\end{array}$ & $\begin{array}{l}\mathrm{EC} \\
(\mathrm{mS} / \mathrm{cm})\end{array}$ \\
\hline \multirow[t]{3}{*}{ HI-mix } & $1-2$ & -3.6 & 3.4 & 9.2 & -1.4 & 1.0 & 9.2 & 1.33 \\
\hline & $1-1$ & 22.5 & 2.3 & 9.2 & 6.4 & 1.0 & 9.2 & 1.33 \\
\hline & $2-1$ & 21.6 & 4.7 & 9.2 & 6.7 & 1.0 & 9.2 & 1.35 \\
\hline \multirow[t]{3}{*}{ Flocc } & $1-2$ & -4.8 & 1.4 & 9.1 & -6.5 & 0.7 & 9.2 & 1.36 \\
\hline & $1-1$ & 3.2 & 0.8 & 9.1 & -1.5 & 0.5 & 9.1 & 1.38 \\
\hline & $2-1$ & 14.0 & 1.4 & 9.2 & 3.1 & 0.3 & 9.2 & 1.38 \\
\hline
\end{tabular}

The values presented are averages calculated from 3 (charge density) or 6 independent measurements $(\zeta$-potential) 


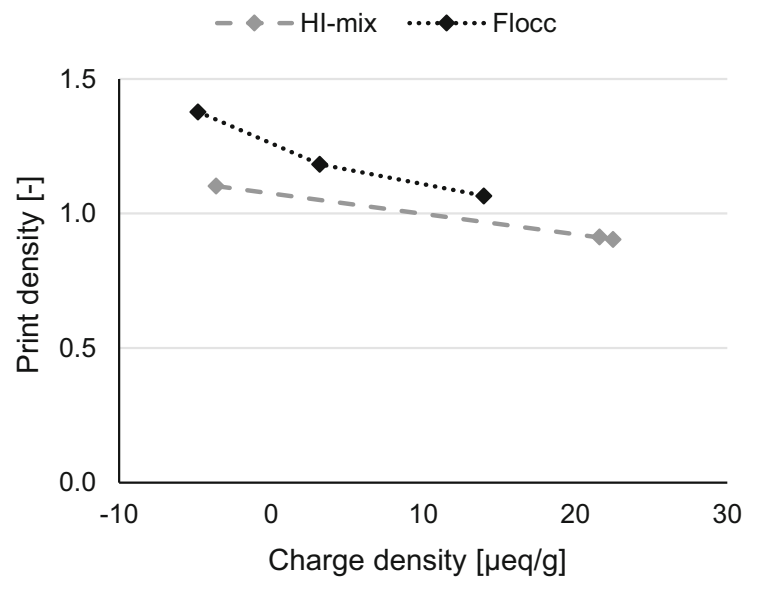

Fig. 9 Print density of black ink plotted against charge density of the re-dispersed composite sheets. The print density value used in the plot was achieved for samples which were not calendared

expected to fix and immobilize the anionic dye via ionic interactions (Kettle et al. 2010). In the present work, however, the print density decreased when the substrate became less anionic or more cationic. This may be due to unfavorable solvent absorption and ink spreading which caused by the characteristic substrate porosity.

A surface structure with a high concentration of fine diameter pores combined with a large pore volume is generally thought to offer efficient separation of the ink vehicle from the colorant (Lamminmäki et al. 2011; Schoelkopf et al. 2000), but in the composite sheets, the ink was probably absorbed into PCC-rich areas, due to their more open structure. The designed composite sheet could not be compared with previous work on coated paper substrates since it lacked a separate binder such as polyvinyl alcohol (PVOH) (Lamminmäki et al. 2011; Hladnik and Muck 2002) or anionic styrene acrylate latex (Lamminmäki et al. 2011). The role of the binder and its effect on the porosity of a PCC-based coating was reported by Mielonen et al. (2018), who reported results similar to the present results when no binder was used.

We suggest that that increasing the proportion of PCC in the sheets not only changed the charge density and charge nature, but also affected the ink absorption mechanism. While the porosity decreased during calendering in the case of sheet made without flocculating agent, the porous PCC layer formed on the sheet surface was able to provide absorption pathways deeper into the sheet structure. The more even distribution of MFC and PCC, observed in the composite sheets made with the flocculating agent, appeared to provide fewer absorption pathways into the sheet structure. Similar results have been reported by Penttilä et al. (2012) who reported open structures for filler-nanocellulose substrate sheets when rosetteshaped PCC was used. They linked the open structure to ink penetration into the sheet, also for calendered sheets (Penttilä et al. 2012).

\section{Conclusions}

In this work, composite sheets were prepared by synthesizing cationic PCC which was mixed in different ratios with microfibrillated cellulose providing sheets with mineral contents between 29 and 63 wt $\%$. The agglomeration and interaction between the cationic PCC and microfibrillated cellulose were adjusted with an anionic polyacrylamide flocculating agent. Sheets were densified to different extents by calendering in order to alter their print-related properties. The composite sheet densification decreased the porosity and increased the smoothness, but also reorganized the filler, which was found to affect negatively to the print quality and especially print density due to changes in ink absorption. The sheets showed a greater stabilization against the material flow of the mineral filler when an anionic flocculation aid was added. This was attributed to changes in flocculation behavior of MFC and PCC, and more precisely to the formation of hard flocs instead of the soft flocs which were probably formed when the sheets were prepared without the anionic flocculating agent.

PCC distribution, PCC agglomeration and PCC-toMFC ratio significantly affected the water and anionic ink absorption, and thus the print quality. Significantly, the slower absorption of water in structures containing the anionic flocculating agent suggested a more homogeneous structure in terms of water absorption, rather than a change in electrochemical interaction between the sheets and the dye. These findings support the thought that calendering can be used to alter and improve the printing properties of PCC-MFC composite sheets, which can potentially be helpful when preparing such sheets e.g. for printed electronics substrates. 
Acknowledgments Stora Enso Oyj is acknowledged for financial support of the project. Dr Anthony Bristow is thanked for linguistic revision of the work. Nikolai Ponomarev is thanked for help with the composite sheet preparation.

Funding Open access funding provided by LUT University. This research did not receive any specific grant from funding agencies in the public, commercial, or not-for-profit sectors.

Availability of data and material Not applicable.

\section{Compliance with ethical standards}

Conflict of interest None.

Code availability Not applicable.

Open Access This article is licensed under a Creative Commons Attribution 4.0 International License, which permits use, sharing, adaptation, distribution and reproduction in any medium or format, as long as you give appropriate credit to the original author(s) and the source, provide a link to the Creative Commons licence, and indicate if changes were made. The images or other third party material in this article are included in the article's Creative Commons licence, unless indicated otherwise in a credit line to the material. If material is not included in the article's Creative Commons licence and your intended use is not permitted by statutory regulation or exceeds the permitted use, you will need to obtain permission directly from the copyright holder. To view a copy of this licence, visit http://creativecommons.org/licenses/by/4.0/.

\section{References}

Aloi FG, Trsksak RM (1998) Retention in neutral and alkaline papermaking. In: Gess J.M (ed) Retention of fines and fillers during papermaking. Tappi Press, Atlanta, pp 61-108

Beghello L (1998) The tendency of fibers to build flocs. Dissertation, Åbo Akademi University

Bollström R, Määttänen A, Tobjörk D, Ihalainen R, Kaihovirta N, Österbacka R, Peltonen J, Toivakka M (2019) A multilayer coated fiber-based substrate suitable for printed functionality. Org Electron 10:1020-1023. https://doi.org/ 10.1016/j.orgel.2009.04.014

Brodin FW, Gregersen ØW, Syverud K (2014) Cellulose nanofibrils: challenges and possibilities as a paper additive or coating material-a review. Nord pulp pap res $j$ 29(1):156-166. https://doi.org/10.3183/npprj-2014-29-01p156-166

Cho B-U, Garnier G, van de Ven TGM, Perrier M (2006) A bridging model for the effects of a dual component flocculation system on the strength of fiber contacts in flocs of pulp fibers: Implications for control of paper uniformity. Colloids Surf A Physicochem Eng Asp 287(1-3):117-125. https://doi.org/10.1016/j.colsurfa.2006.03.029
Dimic-Misic K, Gane PAC, Paltakari J (2013) Micro- and nanofibrillated cellulose as a rheology modifier additive in CMC-containing pigment-coating formulations. Ind Eng Chem Res 52(45):16066-16083. https://doi.org/10.1021/ ie 4028878

Dimic-Misic K, Maloney T, Liu G, Gane P (2017) Micro nanofibrillated cellulose (MNFC) gel dewatering induced at ultralow-shear in presence of added colloidally unstable particles. Cellulose 24:1463-1481. https://doi.org/10. 1007/s10570-016-1181-x

Gebauer D, Oliynyk V, Salajkova M, Sort J, Zhou Q, Bergström L, Salazar-Alvarez G (2011) A transparent hybrid nanocrystalline cellulose and amorphous calcium carbonate nanoparticles. Nanoscale 3(9):3563-3566. https://doi. org/10.1039/C1NR10681C

Hladnik A, Muck T (2002) Characterization of pigments in coating formulations for high-end ink-jet papers. Dyes Pigm 54(3):253-263. https://doi.org/10.1016/S01437208(02)00050-5

Junka K, Filpponen I, Lindström T, Laine J (2013) Titrimetric methods for the determination of surface and total charge of functionalized nanofibrillated/microfibrillated cellulose (NFC/MFC). Cellulose. https://doi.org/10.1007/s10570013-0043-z

Kettle J, Lamminmäki T, Gane P (2010) A review of modified surfaces for high speed inkjet coating. Surf Coat Technol 204(12-13):2103-2109. https://doi.org/10.1016/j.surfcoat. 2009.10.035

Korhonen J, Laine J (2014) Flocculation and retention of fillers with nanocelluloses. Nord pulp pap res j 29(1):119-128. https://doi.org/10.3183/npprj-2014-29-01-p119-128

Korhonen MHJ, Sorvari A, Saarinen T, Seppälä J, Laine J (2014) Deflocculation of cellulosic suspensions with anionic high molecular weight polyelectrolytes. Bioresources 9(2):3550-3570. https://doi.org/10.15376/biores. 9.2.3550-3570

Lamminmäki TT, Kettle J, Gane PAC (2011) Absorption and adsorption of dye-based inkjet inks by coating layer components and the implications for print quality. Colloids Surf A Physicochem Eng Asp 380(1):79-88. https://doi.org/10. 1016/j.colsurfa.2011.02.015

Lavoine N, Desloges I, Khelifi B, Bras J (2014) Impact of different coating processes of microfibrillated cellulose on the mechanical and barrier properties of paper. J Mater Sci 49(7):2879-2893. https://doi.org/10.1007/s10853-0137995-0

Mielonen K, Laukala T, Lyytikäinen J, Backfolk K (2018) The effect of anionic-cationic multilayering and microstructure on dye-based ink absorption. Chem Eng Sci 190:396-404. https://doi.org/10.1016/j.ces.2018.06.049

Penttilä A, Sievänen J, Torvinen K, Ojanperä K, Ketoja JA (2012) Filler-nanocellulose substrate for printed electronics: experiments and model approach to structure and conductivity. Cellulose 20(3):1413-1424. https://doi.org/ 10.1007/s10570-013-9883-9

Rantanen J, Dimic-Misic K, Kuusisto J, Maloney TC (2015) The effect of micro and nanofibrillated cellulose water uptake on high filler content composite paper properties and furnish dewatering. Cellulose 22:4003-4015. https://doi.org/ 10.1007/s10570-015-0777-x 
Ridgway CJ, Gane PAC (2012) Constructing NFC-pigment composite surface treatment for enhanced paper stiffness and surface properties. Cellulose 19:547-560. https://doi. org/10.1007/s10570-011-9634-8

Schoelkopf J, Ridgway CJ, Gane PAC, Matthews GP, Spielmann DC (2000) Measurement and network modeling of liquid permeation into compacted mineral blocks. J Colloid Interface Sci 227:119-131. https://doi.org/10.1006/jcis. 2000.6885

Sorvari A, Saarinen T, Haavisto S, Salmela J, Vuoriluoto M, Seppälä J (2014) Modifying the flocculation of microfibrillated cellulose suspensions by soluble polysaccharides under conditions unfavorable to adsorption. Carbohydr Polym 106:283-292. https://doi.org/10.1016/j.carbpol. 2014.02.032

Svending P (2014) Commercial break-through in MFC processing. In: 2014 TAPPI international conference on nanotechnology for renewable materials. Vancouver, British Columbia, Canada, 23-26 June

Timofeev O, Torvinen K, Sievänen J, Kaljunen T, Kouko J, Ketoja JA (2014) Drying of pigment-cellulose nanofibril substrates. Materials 7(10):6893-6907. https://doi.org/10. 3390/ma7106893
Torvinen K, Lehtimäki S, Keränen JT, Sievänen J, Vartiainen J, Hellén E, Lupo D, Tuukkanen S (2015) Pigment-cellulose nanofibril composite and its application as a separatorsubstrate in printed supercapacitors. Electron Mater Lett 11(6):1040-1047. https://doi.org/10.1007/s13391-0155195-6

Torvinen K, Sievänen J, Hjelt T, Hellén E (2012) Smooth and flexible filler-nanocellulose composite structure for printed electronics applications. Cellulose 19(3):821-829. https:// doi.org/10.1007/s10570-012-9677-5

Unbehend JE, Britt KW (1982) Retention, drainage, and sheet consolidation. Ind Eng Chem Prod Res Dev 21(2):150-153. https://doi.org/10.1021/i300006a004

Yan J (2009) The influence of chemical and mechanical flocculation on paper formation as assessed by the grammage probability distribution. Dissertation, Miami University

Yang G, Kecheng L, Zhijie W (2006) The influence of pulp furnish components on the property of supercalendered paper. Pulp Pap Canada 108(1):44-49

Publisher's Note Springer Nature remains neutral with regard to jurisdictional claims in published maps and institutional affiliations. 